\title{
Numerical modeling of the stress-strain state of peripheral massif in the vicinity of mine workings
}

\author{
Anastasiya Nikitina $^{1 *}$, Dmitriy Borzykh ${ }^{1}$, Sergey $\mathrm{Rib}^{1}$, Aleksandra Lesnykh ${ }^{1}$, \\ and Tonglin $\mathrm{Zhao}^{2}$ \\ ${ }^{1}$ Siberian State Industrial University, Novokuznetsk, 654000, Russia \\ ${ }^{2}$ University of Science and Technology Liaoning, Anshan, 14051, China
}

\begin{abstract}
In the process of numerical studies, the stress-strain state of the rock massif around the mine working driven at a depth of $600 \mathrm{~m}$ was determined. The article presents the analysis of the distribution of total vertical and horizontal stresses isolines in the working roof, as well as the ratio of the residual strength of rocks to the initial. The influence of the roof bolting on the displacement of working contour was established. Dangerous zones in the near-contour rocks of preparatory working were identified. The maximum exposure area of unsecured part of the roof during driving the workings in seam 3-3a was established.
\end{abstract}

\section{Introduction}

The complexity of the task of increasing the stability of rock outcrops in mines is largely conditioned by a wide variety of mining and geological conditions - the structure and strength of the enclosing rocks, thickness of seams and rocks, etc. The loss of rocks stability occurs mainly due to the fact that their weight $G$ is greater than the adhesion force $P$ at the contact with the overlying rocks:

$$
G \geq P
$$

When the condition $\mathrm{G}<\mathrm{P}$ is fulfilled, it is advisable to carry out mining with preservation of the roof, i.e., without roof cutting. In these conditions, dangerous deformations and destruction of roof rocks occur under the influence of stresses changing in them during the workings operation [1-4]. Loss of rock stability occurs when the long-term strength of the rocks is less than the stresses in the rocks. The strength of the roof rocks depends on layering, fracturing and other macro- and micro-structural defects. Due to the layering, the strength of the roof rocks decreases by 1.5- 4 times, and due to fracturing - by 3-15 times.

\footnotetext{
*Corresponding author: nik.am_78@mail.ru
} 
An increase in the layers thickness of roof rocks, all other things being equal, is accompanied by a decrease in the collapse of roof rocks into the face area.

In the existing mining conditions, the solutions in the approved technical documentation ensure exposures of unsecured part of the roof during mine workings in seam 3-3a with a stope of 1.8 meters long. To substantiate the possibility of high-speed mine workings, it is necessary to determine the stable roof spans and the time of its stability before collapsing in the face in the conditions of existing development face. All the variety of techniques and methods for carrying out mine workings is reduced to a technological scheme, for which, depending on the tunneling equipment and parameters of the roof bolting and mining conditions, a span of the roof exposure before support erection equaling $3.8 \mathrm{~m}$ is selected (Fig. 1).

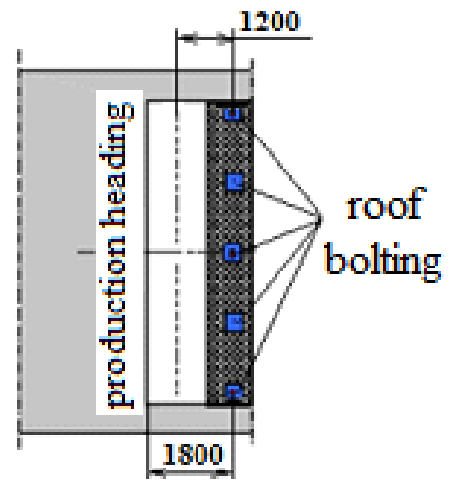

(a)

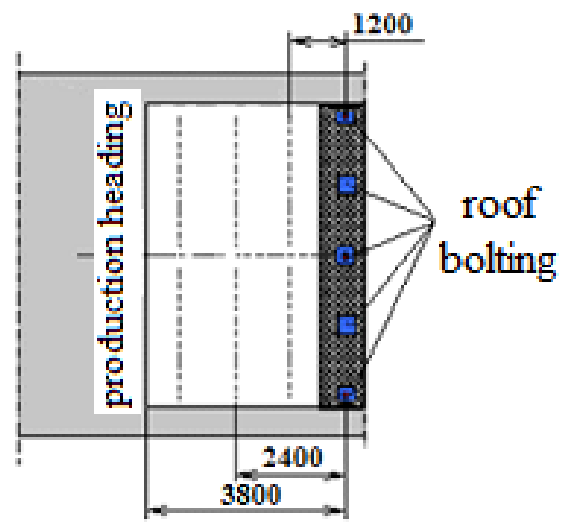

(b)

Fig. 1. Roof spans $1.8 \mathrm{~m}$ (a) and $3.8 \mathrm{~m}$ (b) before support erection in the production heading.

A research methodology was developed in order to study geomechanical processes in the coal-rock massif in the conditions of Shakhta Alardinskaya LLC and in accordance with the task set, which is the determination of the maximum exposure area of of the unsecured part of the roof during mining in seam 3-3a to a mining depth of $600 \mathrm{~m}$.

\section{Research methodology}

The methodology includes the characteristics of methods and objects of research (Fig. 2). The finite element method (FEM) is chosen as a tool for calculating the stress-strain state (SSS) of a coal-rock mass; the algorithm of the method is implemented in the algorithmic FORTRAN language.

The essence of the finite element method lies in the numerical solution of systems of differential equations of geomechanics. For this, the infinite studied area is divided into a set of finite elements, that is, a continuous function is approximated by a set of piecewise continuous functions. To solve the set tasks, a two-dimensional problem is solved, which takes into account the layered structure of the rock mass, stratigraphy and lithology, geological disturbances, the shape and size of the mined-out space [5-8].

The solution is carried out in the elastoplastic formulation. The CoalPillar software package based on the FEM is used. The complex of problem-oriented programs CoalPillar, with the finite element mesh method is intended for two-dimensional modeling of geomechanical processes in a coal-rock mass, taking into account the influence of its layering and heterogeneous structure in the form of rock layers, solid inclusions, mud 
zones, disjunctive geological disturbances and a system of interfering treatment and development workings.

Evaluation of the quality of model automatic discretization into finite elements is carried out in the Surfer program. The geometric model is presented in the form of a vertical section, perpendicular to the axes of mine workings in seam 3-3a. The coordinate origin of conventional coordinate system is taken at the intersection of the roof and the right side of the mine working. Fig. 3 shows a fragment of the model discretization into finite elements. In the event of a discrepancy between the position or size of the finite elements of the real situation, the initial data is corrected.

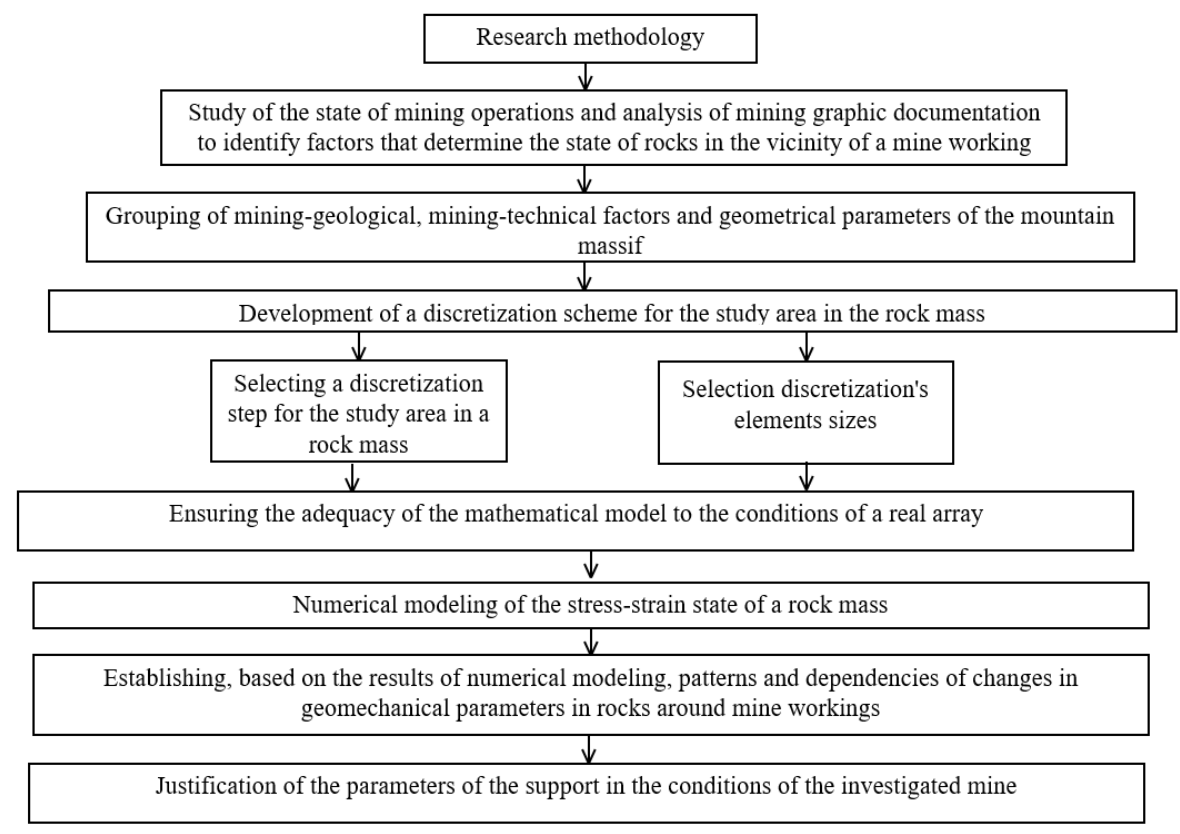

Fig. 2. Research methodology for geomechanical processes.

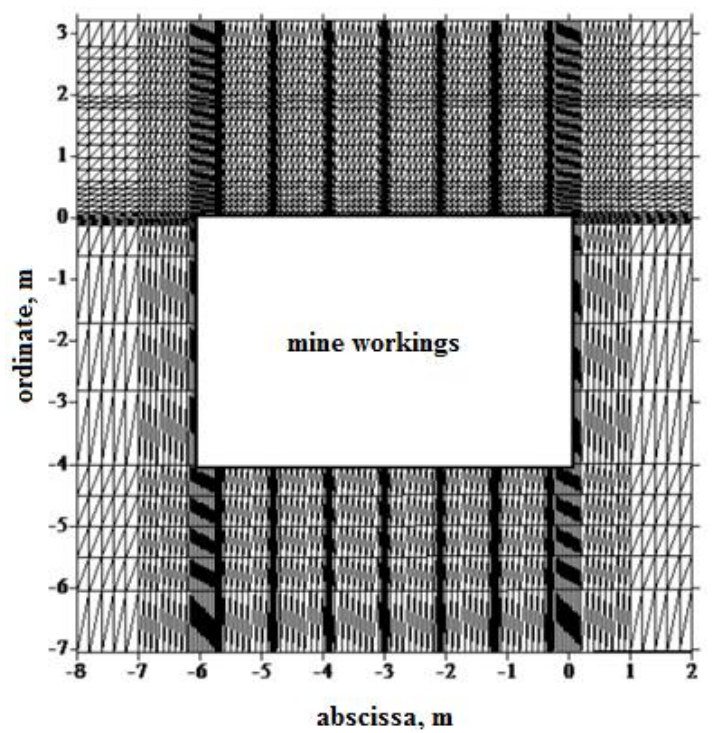


Fig. 2. Fragment of the discretization scheme of investigated geometric model of a coal-rock massif into finite elements.

An algorithm for calculating the SSS parameters of a coal-rock mass in the form of a complex of problem-oriented computer programs CoalPillar for numerical modeling is shown in Fig. 4. The number of layers in the model is taken to be 100, and their thickness is from 0.05 to $100 \mathrm{~m}$. The number of vertical lines per the geometric model is taken 200 with a distance between them from 0.01 to $100 \mathrm{~m}$. Layers of significant thickness are divided into sublayers to improve the accuracy of calculating the SSS parameters. The geometric model is divided into a set of finite elements -40400 triangles.

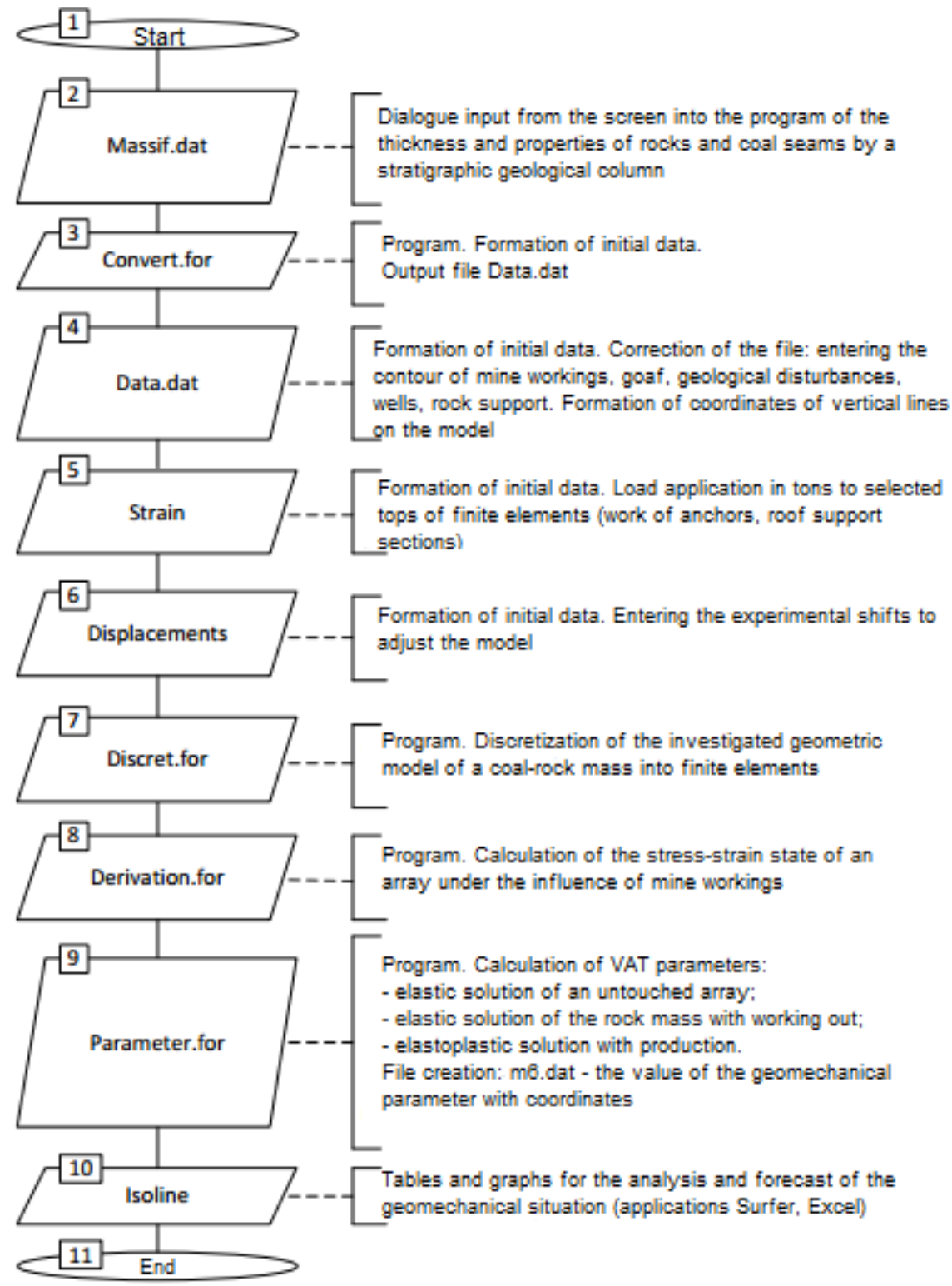


Fig. 4. Algorithm for calculating the SSS parameters of the coal-rock mass.

Fig. 5 shows a mining model for seam 3-3a when driving sections with and without support.

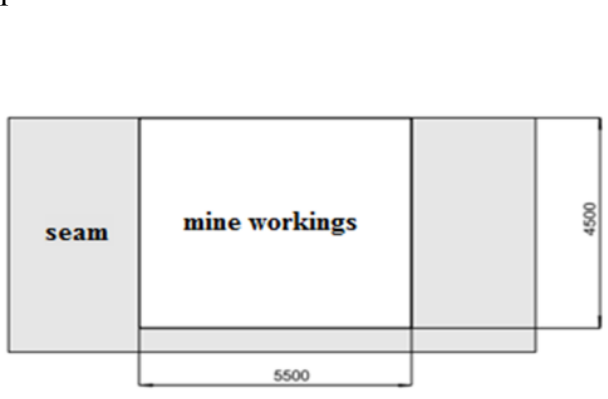

(a)

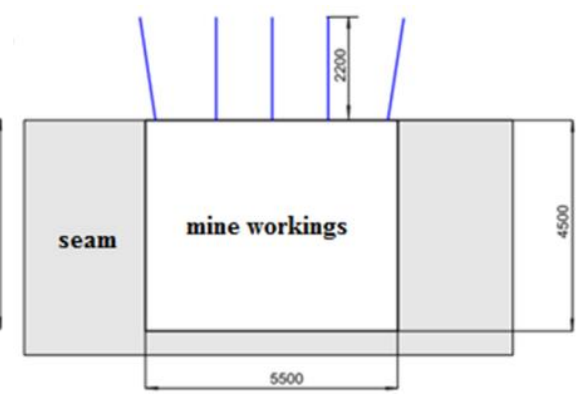

(b)

Fig. 5. Options of working modeling.

The dimensions of geometrical model along the strike are taken to be $100 \mathrm{~m}$, the estimated seam depth 3-3a is $600 \mathrm{~m}$. When modeling, the data of geological column were taken as the initial data: siltstone with a thickness of 0.5-6.0 m and a strength up to $65 \mathrm{MPa}$ lies in the top of the reservoir. The width of the mine working was taken up to $6.0 \mathrm{~m}$, the height of $4.5 \mathrm{~m}$, the average density of rocks is $2500 \mathrm{t} / \mathrm{m}^{3}$. The following initial data were taken into account: development depth up to $600 \mathrm{~m}$, formation dip angle up to $12^{\circ}$, structural weakening coefficient in the transition from the strength of the laboratory specimen to the strength in the massif 0.5 , the lateral pressure coefficient in the intact massif taking into account the seismic activity of the southern Kuzbass $\lambda=0.5$.

\section{Results and discussion}

Based on the results of mathematical modeling and analysis of mining and technological factors that determine the main influence on the stability of rock exposures, it was established:

- with an increase in the width of the working from 5.5 to $6 \mathrm{~m}$, the displacement in the working increases by $6-8 \%$;

- an increase in the depth of the mine workings in seam 3-3a from 300 to $600 \mathrm{~m}$, leads to an increase in roof displacements in rocks with $\sigma_{\text {com }}<45 \mathrm{MPa}$ by 3- .5 times and with $\sigma_{\text {com }}=45-80 \mathrm{MPa}$ by 2-2.4 times;

- with the strength of the layers for uniaxial compression of 55-65 $\mathrm{MPa}$ and their thickness exceeding $0.8 \mathrm{~m}$, the rock exposures of the roof remain stable for more than 2 hours. When the layer thickness is from 0.1 to $0.4 \mathrm{~m}$ and the strength of the rocks under compression is up to $40 \mathrm{MPa}$, the stable state time is maintained within one hour, and when the layer thickness is less than $0.1 \mathrm{~m}$, which is usually typical for false roofs, the time of their stable state ranges from 10 to 20 minutes;

- the roof displacement before entering the abutment pressure zone usually occurs uniformly, and in the abutment pressure zone it proceeds 1.5-2.5 times faster. Fig. 6 shows the isolines of the ratio of residual rock strength to the original strength $\left(K_{t r}\right)$. Based on the results of comparing the calculated values of the strength ratios and examining the state of the rocks on the working contour, it was found that when the ratio $K_{t r} \leq 0.5$, coal or rocks are destroyed in the form of lumps with pouring into the working. When $0.5<K_{t r} \leq 0.7$, cracks are formed, this area is considered as a pre-fracture zone, with $K_{t r}>0.7$ additional cracks of technogenic origin, as a rule, are absent on the excavation contour. The following changes 
occurred in the roof rocks: the width of the pre-fracture arch (isoline with $\mathrm{K}_{t r}=0.6$ ) decreased from $3.5 \mathrm{~m}$ to $2 \mathrm{~m}$.

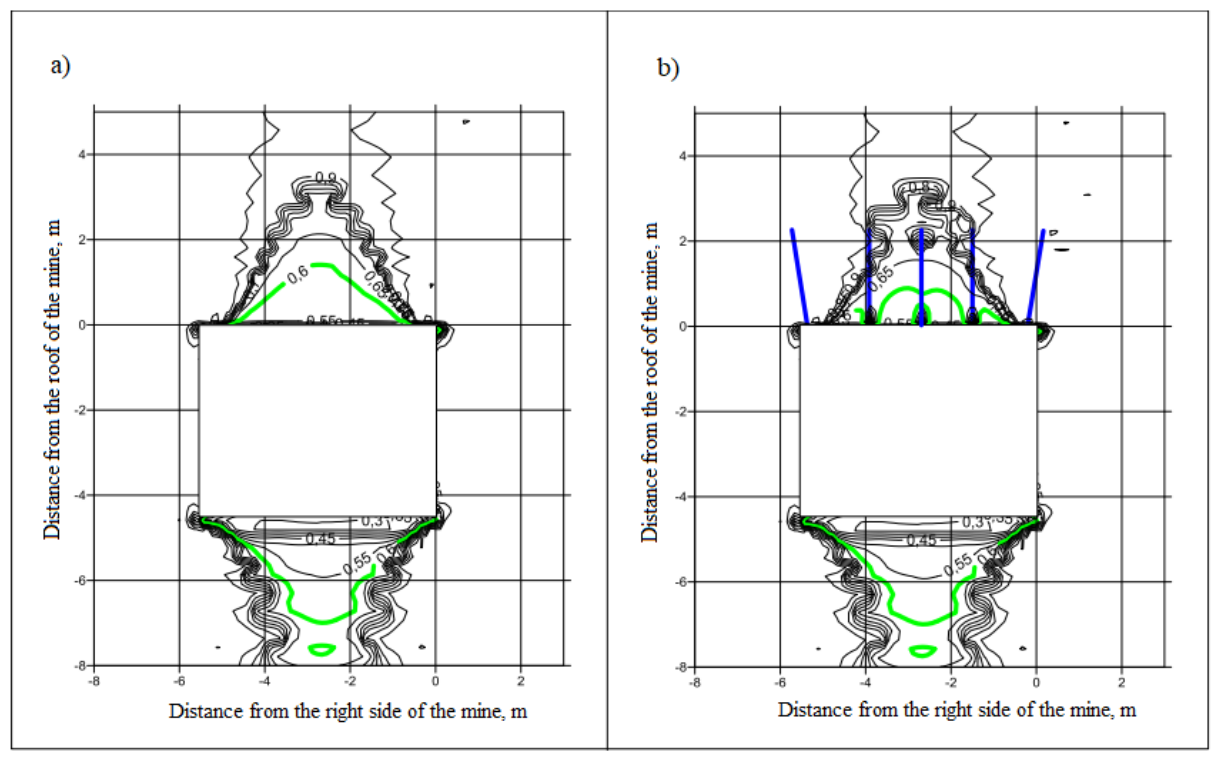

Fig. 6. Distribution of the isolines of residual strength ratio to the original in the vicinity of the mine working (along the working section in the place of the first row of bolting at a depth of entry of 3.8 $\mathrm{m})$ : $\mathrm{a}$ - without support; $\mathrm{b}$ - with five anchors.

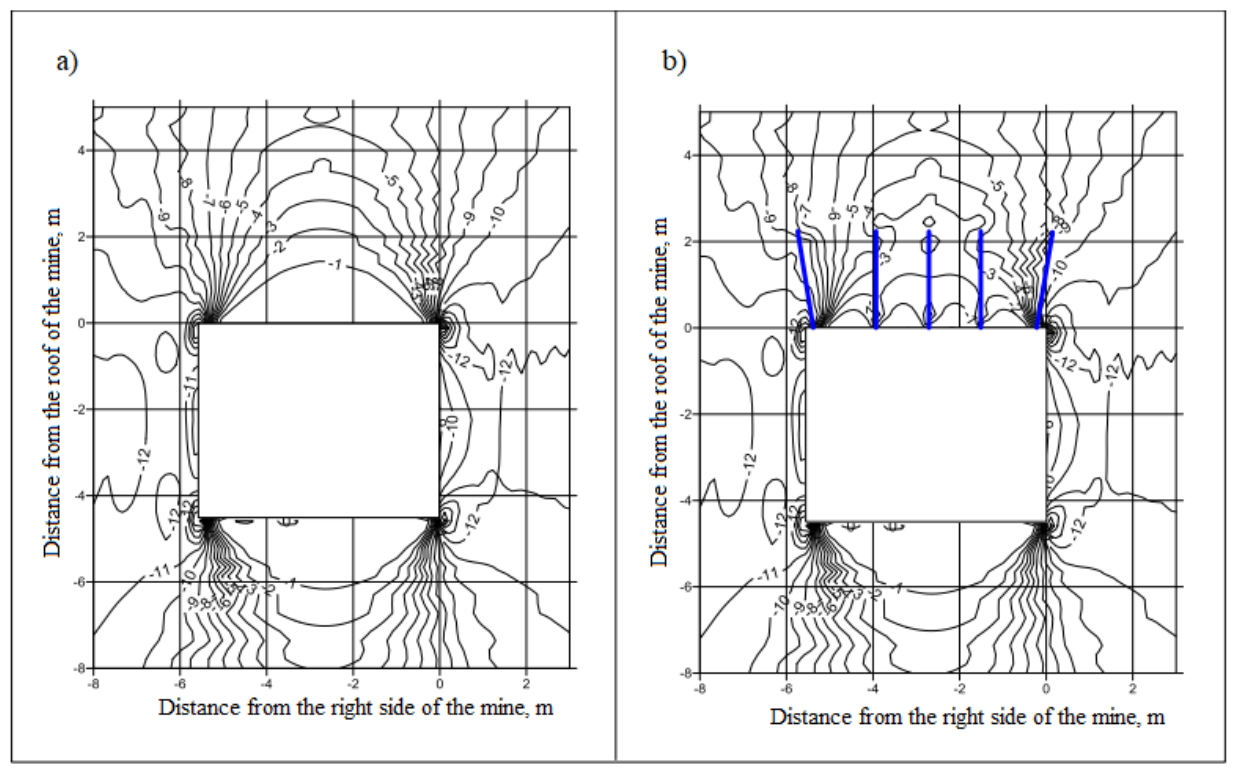

Fig. 7. Distribution of total vertical stresses isolines in the vicinity of mine working (along the section of the working in the place of the second row of anchor support at a stope depth of $3.8 \mathrm{~m}$ ): a-without support; $\mathrm{b}$ - with five anchors.

From the comparison of the graphs in Fig. 7 and 8, it follows that the support erection led to an increase in compressive stresses in the zone of anchors. This happened due to the 
hardening of coal and rocks and preservation of their bearing capacity. Localized zones of hardening appeared in the vicinity of the anchor rods.

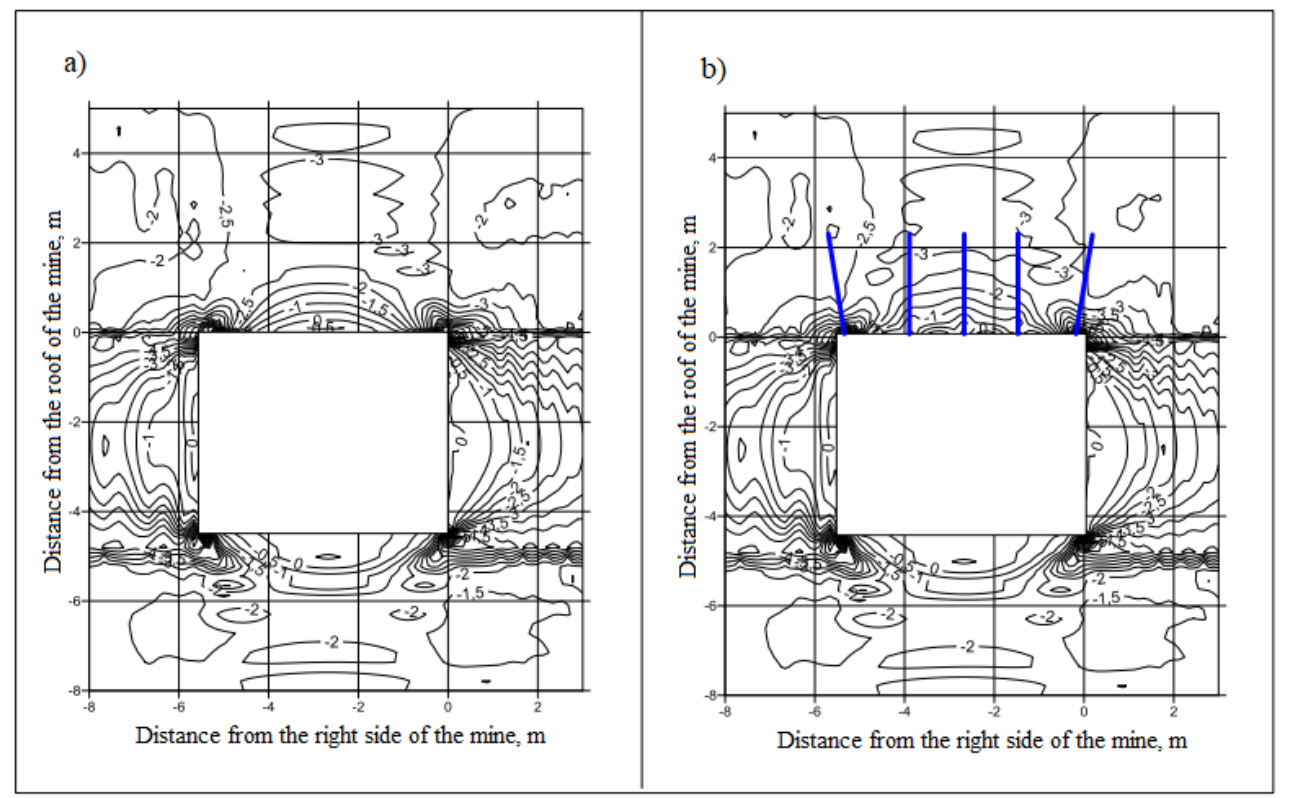

Fig. 8. Distribution of total horizontal stresses isolines in the vicinity of mine working (along the section of the working in the place of the third row of anchor support at a stope depth of $3.8 \mathrm{~m}$ ): a without support; $b$ - with five anchors.

The support also influenced the displacement of the working contour. After support erection, the roof-soil convergence decreased by $16 \%$, and the side-to-side convergence by 1.6 times (Fig. 9).

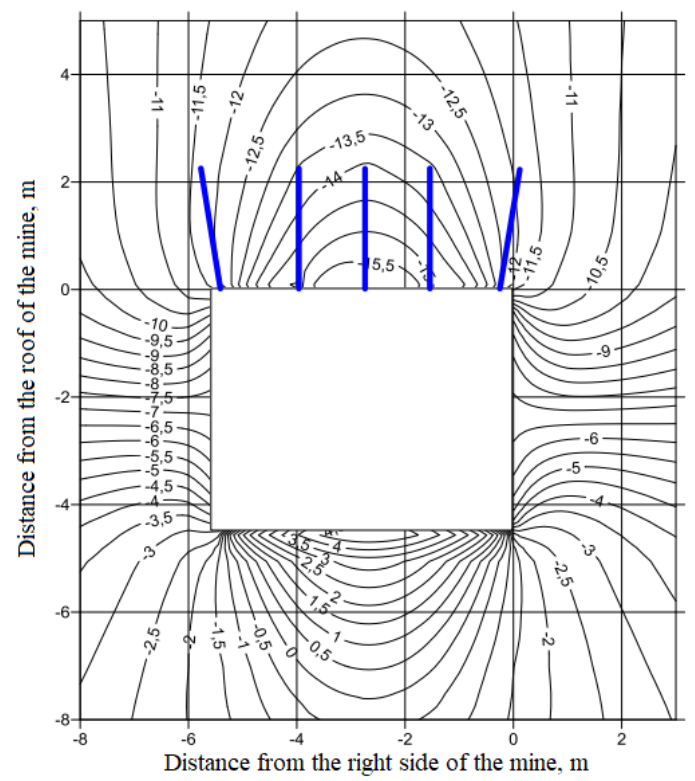


Fig. 9. Distribution of additional vertical displacements isolines in the vicinity of mine workings (along the section of the working in the place of the first row of bolting at a stope depth $3.8 \mathrm{~m}$ ).

\section{Conclusions}

From the results of mathematical research, namely, the analysis of distribution of total vertical and horizontal stresses isolines in the mine roof, as well as the ratio of residual strength of rocks to the original, it follows:

- the most obvious areas of layering are traced in the center of the roof of mine working,

- probable formation of crack systems in the unsecured part of the mine is possible to a height from the roof up to $1.6 \mathrm{~m}$,

- the hazardous zones identified during the modeling in the near-contour rocks of the mine workings will make it possible to correct the technical documentation for carrying out and supporting the mine workings,

- the obtained parameters of the roof bolting will reduce the size of the hazardous zone in the vicinity of development working: the maximum exposure of the working roof can be up to $3.8 \mathrm{~m}$ for the given mining and geological conditions.

\section{References}

1. I.V. Tretenkov, Life safety of enterprises in coal regions, 85-87 (KuzSTU, Kemerovo, 2000)

2. I.L. Chernyak, Yu.I. Burchakov, Rock pressure control in the development workings of deep mines (Moscow, 1984)

3. V.F. Demin, V.S. Portnov, et al., Ugol, 11, 70-73 (2013)

4. D.V. Yakovlev, Ugol, 7, 12-14 (2014)

5. D.M. Borzykh, S.V. Rib, et al., Cert. of reg. of electr. res., No. 20629 (2014)

6. Yu.M. Govorukhin, S.V. Rib, et al., Gornyi Zhurnal, 4, 23-26 (2019)

7. V.N. Vylegzhanin, P.V. Egorov, V.I. Murashev, Structural models of a rock mass in the mechanism of geomechanical processes (Novosibirsk, 1990)

8. A. N. Domrachev, S.V. Rib, A.M. Nikitina, Bulletin of TSU. Geosciences, 4, 81-90 (2016) 